\title{
Peroxiredoxin 6 Serum Levels and Risk of Neutropenic Infections in Diffuse Large B-cell Lymphoma
}

\author{
ESA JARKKO MIKAEL KARI ${ }^{1}$, MILLA ELVI LINNEA KUUSISTO ${ }^{1}$, JAN BÖHM ${ }^{2}$, \\ KIRSI-MARIA HAAPASAARI ${ }^{3}$, HANNA-RIIKKA TEPPO ${ }^{3}$, PEETER KARIHTALA $^{1,3}$, \\ ANNA HAKALAHTI ${ }^{1}$, TAINA TURPEENNIEMI-HUJANEN ${ }^{1,3}$ and OUTI KUITTINEN ${ }^{4}$ \\ ${ }^{1}$ Department of Oncology and Radiotherapy, Medical Research Center Oulu, \\ Oulu University Hospital and University of Oulu, Oulu, Finland; \\ ${ }^{2}$ Department of Pathology, Central Finland Central Hospital, Jyväskylä, Finland; \\ ${ }^{3}$ Cancer Research and Translational Medicine Research Unit, Medical Research \\ Center Oulu, Oulu University Hospital and University of Oulu, Oulu, Finland; \\ ${ }^{4}$ Department of Oncology, Faculty of Health Medicine, \\ Institute of Clinical Medicine, University of Eastern Finland, Kuopio, Finland
}

\begin{abstract}
Background/Aim: Diffuse large B-cell lymphoma $(D L B C L)$ is an aggressive malignancy where antioxidant enzyme peroxiredoxin 6 (Prx6) has previously been associated with adverse outcomes. Its systemic effects in DLBCL are unknown. Materials and Methods: This study included 53 patients with DLBCL, five patients with primary central nervous system lymphoma (PCNSL) and 20 healthy controls. The expression of Prx6 was evaluated immunohistochemically in DLBCL tissue samples and compared to its expression in blood serum. Results: Prx6 expression was the highest in healthy controls, followed by DLBCL patients and PCNSL patients. Febrile neutropenic infection after the first treatment course was associated with low pre-treatment Prx6 serum levels $(<14 \mathrm{ng} / \mathrm{ml}) \quad(p=0.025$, OR=8.615, 95\% confidence interval $=1.032-71.933)$. Serum levels of Prx6 recovered after treatment $(p=0.006)$. Conclusion: Patients with low Prx6 levels might be more prone to treatment-related adverse effects through elevated levels of oxidative stress.
\end{abstract}

Diffuse large B-cell lymphoma (DLBCL) is the most common form of non-Hodgkin lymphoma, accounting for $30-40 \%$ of all cases. DLBCL is a group of different diseases that displays considerable variability regarding clinical

Correspondence to: Esa Kari, MD, Ph.D., student, Department of Oncology and Radiotherapy, Oulu University Hospital, P.O. Box 22, Oulu FIN-90029, Finland. Tel: +35 8440333174, e-mail: esa.kari@student.oulu.fi

Key Words: Lymphoma, peroxiredoxin 6, 8-hydroxydeoxyguanosine, diffuse large B-cell lymphoma, primary central nervous system lymphoma, neutropenic infection. presentation and prognosis (1). Oxidative stress markers such as 8-hydroxydeoxyguanosine (8-OHdG) and antioxidant enzymes, thioredoxin and glutamate-cysteine ligase seem to have a prognostic relevance in certain types of DLBCL where they are strongly expressed compared to more indolent types of lymphoma $(2,3)$. Peroxiredoxins (Prxs) are a group of six antioxidant enzymes that reduce hydrogen peroxide. In a recent retrospective immunohistochemical study, strong cytoplasmic intensity of peroxiredoxin 6 (Prx6) in DLBCL was shown to be associated with adverse outcomes in patients, while other Prxs (Prxs 1, 2, 3 and 5) were not associated with disease presentation or prognosis (4).

In the present study, we immunohistochemically assessed 8-OHdG and Prx6 expression in tumour tissue samples and compared the results with their expression in patients' serum to explore their systemic effects. In addition, healthy controls and patients with primary central nervous system lymphoma (PCNSL) were included, in order to evaluate differences between CNS lymphoma and systemic disease.

\section{Patients and Methods}

Patients. A total of 58 patients who had diagnostic blood serum samples available were retrospectively selected for the study. Study subjects comprised 53 patients with DLBCL, five patients with PCNSL and 20 healthy controls. Blood levels of Prx6 and 8-OHdG were measured using ELISA in all participants. Patient serum samples were obtained at the time of diagnosis and again at a median of 9 months, with a range of 1-38 months, after the end of treatment $(n=24)$. Routine diagnostic biopsy samples were immunohisto-chemically stained for Prx6 and 8-OHdG. Five patients with DLBCL were lacking a representative biopsy sample.

Patients were treated at the Oulu University Hospital in 2003-2017. Clinical data were collected from hospital records. Primary treatment regimens of patients with systemic disease consisted of R-CHOP 
(rituximab, cyclophosphamide, doxorubicin, vincristine, prednisolone), or R-CHOP-like-regimens R-CHOEP (R-CHOP with etoposide) or RCEOP (rituximab, cyclophosphamide, epirubicin, vincristine, and prednisolone). PCNSL patients were treated with the Bonn regimen or blood brain barrier-based therapy (5). This study was approved by the Ethics committee of Northern Ostrobothnia Hospital District (11/2014) and was conducted in accordance with The World Medical Association Declaration of Helsinki ethical principles.

Immunohistochemistry and ELISA. Representative tumour areas were fixed in formalin and embedded in paraffin. Three $\mu \mathrm{m}$ sections were cut from the paraffin blocks and placed on SuperFrostPlus glass slides (Menzel-Gläser, Braunschweig, Germany). The sections were deparaffinised in a clearing agent, Histo-Clear (National Diagnostics, Atlanta, GA, USA), and rehydrated in descending ethanol series. Antigen retrieval for each series was performed in a microwave oven using a $10 \mathrm{mM}$ sodium citrate buffer, $\mathrm{pH}$ 6. The sections were cooled to room temperature for $20 \mathrm{~min}$ and then incubated in a $3 \% \mathrm{H}_{2} \mathrm{O}_{2}$ solution for five min to block the endogenous peroxidase activity. The staining was continued using the Dako REAL ${ }^{\mathrm{TM}}$ EnVision $^{\mathrm{TM}}$ Detection System (Dako Denmark A/S, Glostrup, DK) in accordance with the manufacturer's instructions. Primary antibody incubations were carried out in a humidity chamber at room temperature for Prxd6 (LF-MA0018, AbFrontier, Seoul, Republic of Korea) for 30 min using a 1:6000 dilution, and for 8-OHdG (MOG-100P, JaICA, Nikken SEIL Co., Ltd., Shizuoka, Japan) for $1 \mathrm{~h}$ using a 1:100 dilution. Diaminobenzidine (DAB) was used to detect the immunoreaction and the immunostaining of nuclei was performed with Mayer's haematoxylin (Reagena, Toivola, Finland). Finally, the sections were dehydrated and mounted with Histomount (National Diagnostics, Atlanta, GA, USA). All the washes between different steps were performed with phosphate buffered saline (PBS) including $0.05 \%$ Tween- 20 .

The ELISA kits used were LF-EK0206 (AbFrontier, Seoul, Republic of Korea) for Prx6 and the Highly Sensitive 8-OHdG Check kit, KOG-HS10E (JaICA, Shizuoka, Japan) for 8-OHdG. ELISAs were performed in accordance with the manufacturer's instructions.

The analysis of the immunohistochemical staining results was performed by three experienced haematopathologists (J Böhm, KM Haapasaari and HR Teppo) blinded to the clinical data. The staining intensity in cancer cells was recorded separately in the nuclei, cytoplasm and cell membranes. The intensity was categorised as low, moderate or strong.

Statistical analysis. IBM SPSS Statistics V23 for Windows (IBM, Armonk, NY, USA) was used for the statistical analysis. Tests included the Student's $t$-test, Fisher's exact test, Pearson Chi-Square test, Mann-Whitney $U$-test, Kruskal-Wallis test, Spearman correlation and the Wilcoxon Signed Rank Test. Overall survival (OS) was calculated from the date of diagnosis to the date of death or last follow-up date. Disease-specific survival (DSS) was calculated from the date of diagnosis to the date of lymphomaspecific death or last follow-up and relapse-free survival (RFS) was calculated from the time of diagnosis to the time of relapse. $p$-Values of $<0.05$ were considered statistically significant.

\section{Results}

Patient demographics. Patient demographics are presented in Table I. The mean age of the patients was 58.2 years with
Table I. Patient demographics at the time of diagnosis.

\begin{tabular}{|c|c|c|}
\hline & $\mathrm{n}$ & $\%$ \\
\hline \multicolumn{3}{|l|}{ Gender } \\
\hline Male & 32 & 55 \\
\hline Female & 26 & 45 \\
\hline \multicolumn{3}{|l|}{ DLBCL subtype } \\
\hline NOS & 46 & 79 \\
\hline T-cell rich & 6 & 10 \\
\hline EBV DLBCL NOS & 1 & 2 \\
\hline PCNSL & 5 & 9 \\
\hline \multicolumn{3}{|l|}{ B symptoms } \\
\hline None & 26 & 45 \\
\hline Yes & 26 & 45 \\
\hline Data missing & 6 & 10 \\
\hline \multicolumn{3}{|l|}{ Age } \\
\hline$\leq 60$ & 29 & 50 \\
\hline$>60$ & 29 & 50 \\
\hline \multicolumn{3}{|c|}{ Serum lactate dehydrogenase } \\
\hline Normal & 23 & 40 \\
\hline Elevated & 33 & 57 \\
\hline Data missing & 2 & 3 \\
\hline \multicolumn{3}{|l|}{ Stage } \\
\hline I-II & 30 & 52 \\
\hline II-IV & 27 & 46 \\
\hline Data missing & 1 & 2 \\
\hline \multicolumn{3}{|c|}{ WHO performance status } \\
\hline $0-1$ & 38 & 65 \\
\hline$>1$ & 19 & 33 \\
\hline Data missing & 1 & 2 \\
\hline \multicolumn{3}{|l|}{ Extranodal affusion } \\
\hline $0-1$ & 39 & 67 \\
\hline$>1$ & 13 & 23 \\
\hline Data missing & 6 & 10 \\
\hline \multicolumn{3}{|l|}{ IPI } \\
\hline $0-2$ & 30 & 52 \\
\hline $3-5$ & 22 & 38 \\
\hline Data missing & 6 & 10 \\
\hline \multicolumn{3}{|l|}{ Leukocyte count } \\
\hline Low & 1 & 2 \\
\hline Normal & 33 & 57 \\
\hline High & 23 & 39 \\
\hline Data missing & 1 & 2 \\
\hline \multicolumn{3}{|l|}{ Neutrophil count } \\
\hline Low & 2 & 4 \\
\hline Normal & 36 & 62 \\
\hline High & 17 & 29 \\
\hline Data missing & 3 & 5 \\
\hline \multicolumn{3}{|l|}{ Lymphocyte count } \\
\hline Low & 19 & 33 \\
\hline Normal & 29 & 50 \\
\hline Data missing & 10 & 17 \\
\hline \multicolumn{3}{|l|}{ C-reactive protein } \\
\hline Normal & 31 & 43 \\
\hline High & 26 & 45 \\
\hline Data missing & 1 & 2 \\
\hline \multicolumn{3}{|c|}{ Erythrocyte sedimentation rate } \\
\hline Normal & 31 & 53 \\
\hline High & 23 & 40 \\
\hline Data missing & 4 & 7 \\
\hline \multicolumn{3}{|c|}{ Neutropenic infection after the first treatment } \\
\hline No & 40 & 69 \\
\hline Yes & 17 & 29 \\
\hline Data missing & 1 & 2 \\
\hline
\end{tabular}



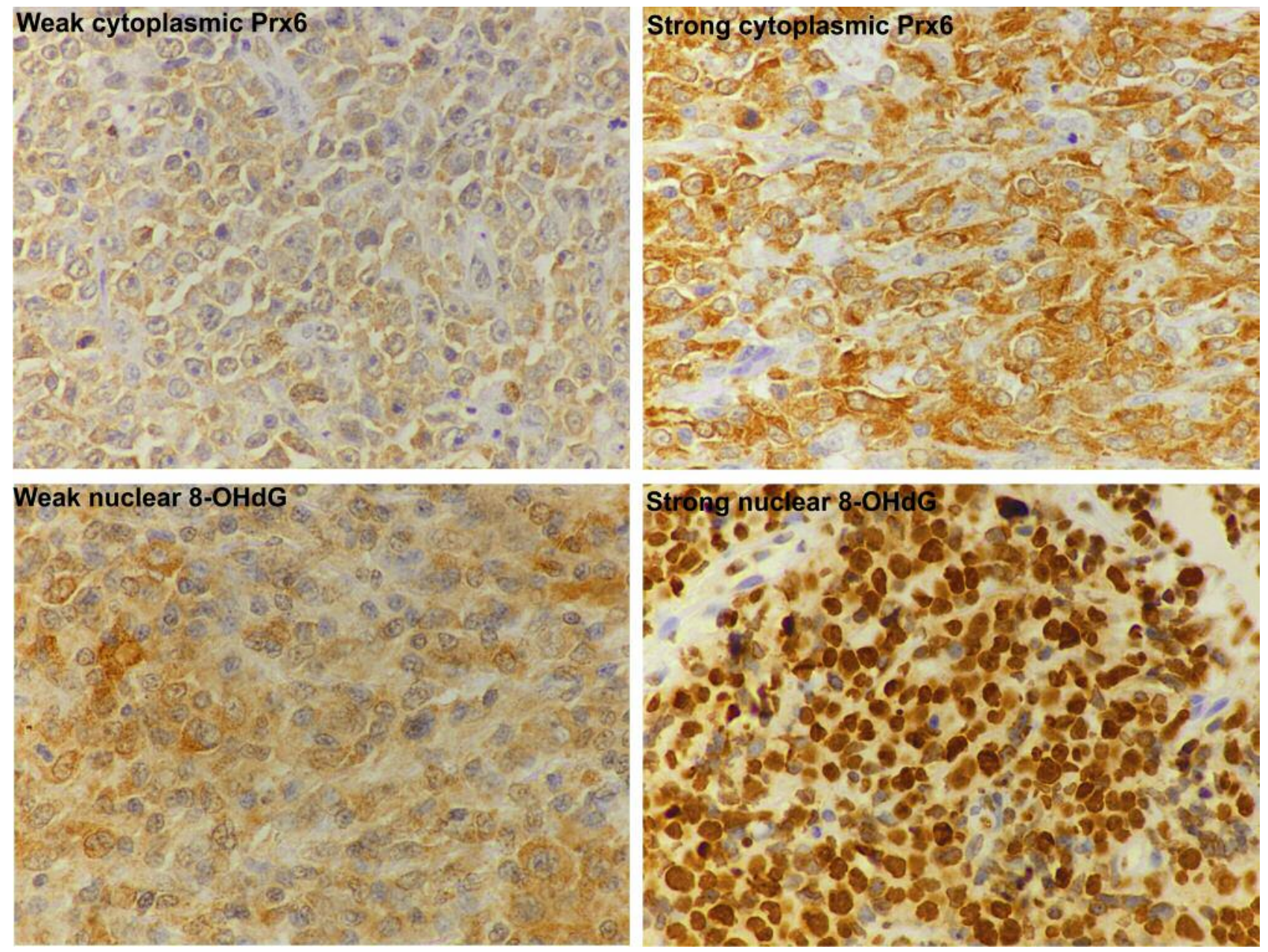

Figure 1. Representative staining from four different DLBCL patients. Clockwise from top left: weak cytoplasmic Prx6 expression, strong cytoplasmic Prx6 expression, strong nuclear 8-OHdG expression and weak nuclear 8-OHdG expression.

a range of 35-89 years, and the mean age of controls was 43.1 years with a range of $26-59$ years $(p<0.001$, Student's $t$-test). Controls had equal sex representation. The median patient follow-up time was 41.5 months. There were 16 deaths, of which ten were disease-specific. Following primary treatment, 53 patients $(91.4 \%)$ achieved complete remission and five patients $(8.6 \%)$ had progressive disease A total of 12 patients $(20.7 \%)$ experienced a relapse. Overall, 28 patients presented with germinal centre phenotype (GC) and 14 with non-GC phenotype; this information was missing from four patients (6). There were also six T-cell rich BCL patients and one EBV+ DLBCL NOS patient. All PCNSL patients represented stage IV disease while the DLBCL patients had roughly equal presentation of all stages $(p=0.014$, Fisher's exact test). There were 17 (29.3\%) neutropenic infections after the first treatment cycle.
Median blood serum albumin in the diagnostic samples was $45 \mathrm{~g} / 1$ among controls and $42 \mathrm{~g} / 1$ among lymphoma patients $(p=0.038$, Mann-Whitney $U$-test). Low albumin levels were associated with B-symptoms $(p=0.007)$, age $>60$ years $(p=0.011)$, poor WHO performance status $(p=0.002)$, IPI index $>2(p=0.019)$, progressive disease $(p=0.020)$, anaemia $(p=0.040)$, and low neutrophil count $(p=0.042)$.

Immunohistochemical analysis. Cytoplasmic Prx6 expression was observed in all DLBCL tissue samples. The median expression in malignant cells was $80 \%$. There was no nuclear expression. 8-OHdG was detected in most nuclei with $80 \%$ median expression. Low to moderate cytoplasmic expression was seen in approximately half of the samples (Figure 1). Prx6 expression was found to be moderate or strong in all tissue samples of PCNSL. Cytoplasmic 

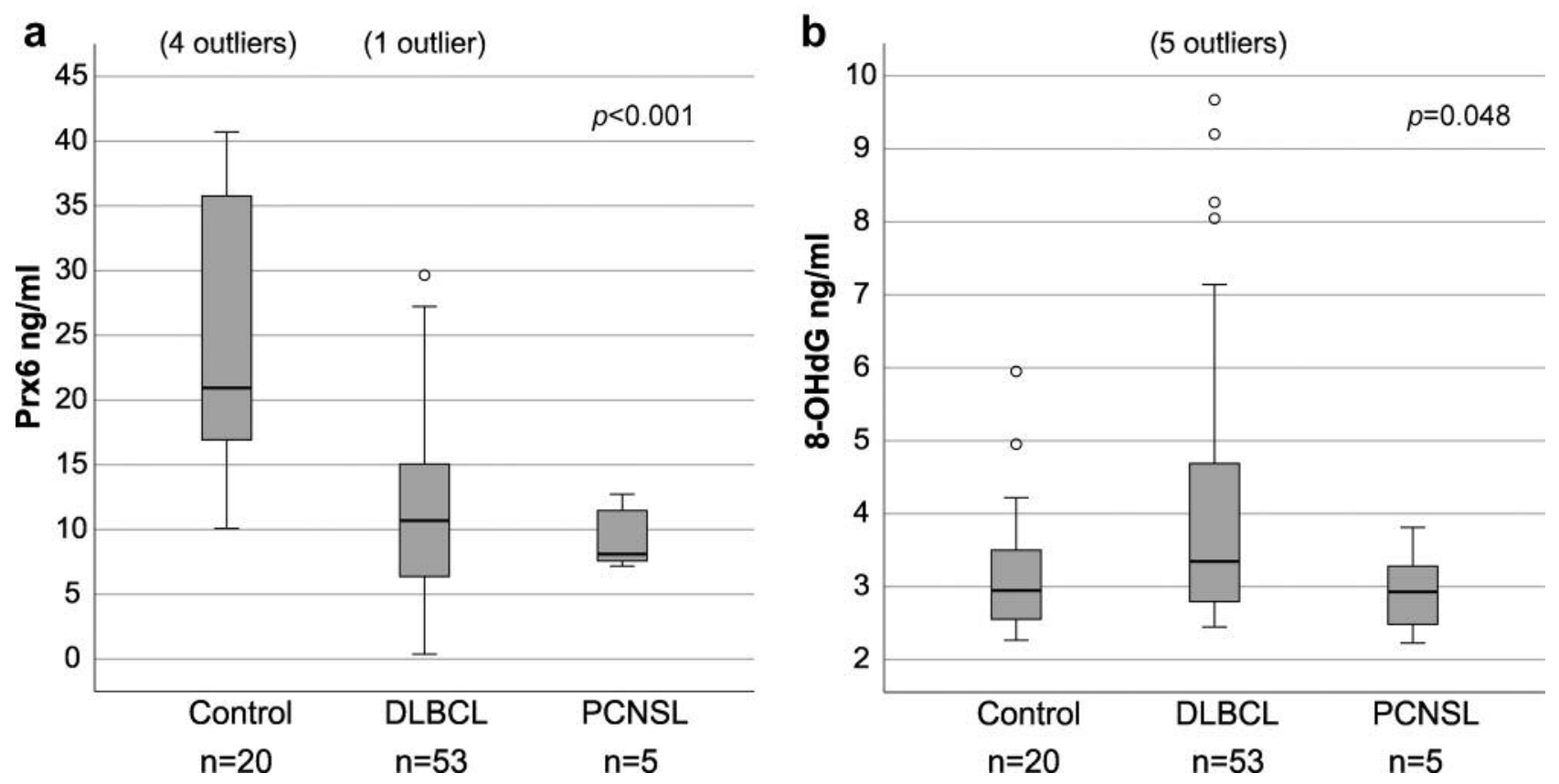

Figure 2. Median serum levels of Prx6 (a) and 8-OHdG (b) among DLBCL patients, PCNSL patients and controls. p-Values represent KruskalWallis test.

expression of $8-\mathrm{OHdG}$ was found in $80 \%$ of PCNSL samples compared to $57.4 \%$ of DLBCL samples $(p=0.399$, Pearson Chi-Square test).

Serum samples. Distribution of Prx6 and 8-OHdG in blood serum samples was skewed. Pre-treatment median serum levels of Prx6 and 8-OHdG differed between the groups (Figure 2). Median serum levels of Prx6 were $10.69 \mathrm{ng} / \mathrm{ml}$ in DLBCL patients, $8.10 \mathrm{ng} / \mathrm{ml}$ in PCNSL patients and $20.94 \mathrm{ng} / \mathrm{ml}$ in controls $(p<0.001$, Kruskal-Wallis test). Median serum levels of 8-OHdG were $3.35 \mathrm{ng} / \mathrm{ml}$ in DLBCL patients, $2.93 \mathrm{ng} / \mathrm{ml}$ in PCNSL patients and $2.95 \mathrm{ng} / \mathrm{ml}$ in controls $(p=0.048$, KruskalWallis test). When a cut-off value of 60 years was used for the whole population (controls were all younger), age showed a statistically significant association ( $p=0.038$, Mann-Whitney $U$-test) with Prx6 levels.

Based on a ROC-curve, $14 \mathrm{ng} / \mathrm{ml}$ of Prx6 and $6 \mathrm{ng} / \mathrm{ml}$ of 8-OHdG were used as cut-off values in the analysis of all clinical variables. These were the best values in discerning controls from patients. There was a significant connection between the presence of a febrile neutropenic infection after the first treatment course and low pre-treatment Prx6 serum levels $(<14 \mathrm{ng} / \mathrm{ml})(p=0.025$, Fisher's exact test) (Figure 3$)$. $38.1 \%$ of patients with Prx6 serum levels under $14 \mathrm{ng} / \mathrm{ml}$ had a neutropenic fever compared to only $6.7 \%$ of patients with higher values $[\mathrm{OR}=8.615(1.032-71.933)]$. High 8-OHdG serum levels were seen in $22.6 \%$ of the DLBCL patients and in none of the PCNSL patients ( $p=0.573$, Fisher's exact test). High Prx6 and 8-OHdG serum levels were associated with each other ( $p=0.025$, Fisher's exact test). At a median of nine months after treatment, Prx6 levels among patients were $19.55 \mathrm{ng} / \mathrm{ml}(\mathrm{n}=24)$ compared to an initial $10.69 \mathrm{ng} / \mathrm{ml}$ $(\mathrm{n}=58)(p=0.006$, Wilcoxon Signed Rank Test). There were no significant associations with survival or differences in chemotherapy received between groups.

Correlations of serum samples and immunohistochemistry. There was a statistically significant negative association between strong nuclear $8-\mathrm{OHdG}$ expression and the presence of $8-\mathrm{OHdG}$ in the cytoplasm $(p=0.036$, Pearson Chi-Square test) and between strong nuclear $8-\mathrm{OHdG}$ expression and low 8-OHdG serum levels ( $p=0.015$, Mann-Whitney $U$-test). Strong cytoplasmic Prx6 expression was also nonsignificantly associated with lower $8-\mathrm{OHdG}$ serum levels ( $p=0.060$, Mann-Whitney $U$-test). There was no significant correlation between the other study parameters (Table II).

Correlations between immunohistochemical expression and clinical data. Strong cytoplasmic Prx6 expression was associated with extranodal DLBCL involvement of more than one site ( $p=0.039$, Fisher's exact test) and a high IPI score (3-5) $(p=0.035$, Fisher's exact test). There were no other correlations between the results of the immunohistochemical analysis and disease presentation. 
Table II. Correlations of serum Prx6 and 8-OHdG levels and their immunohistochemical expression. + stands for positive association and - negative association.

\begin{tabular}{|c|c|c|c|c|}
\hline & $\begin{array}{l}\text { Prx6 cytoplasm } \\
\text { (strong) }\end{array}$ & $\begin{array}{l}\text { 8-OHdG serum levels } \\
(\mathrm{ng} / \mathrm{ml})\end{array}$ & $\begin{array}{l}\text { 8-OHdG present } \\
\text { in cytoplasm }\end{array}$ & $\begin{array}{l}\text { 8-OHdG nucleus } \\
\text { (strong) }\end{array}$ \\
\hline Prx6 serum levels (ng/ml) & $\begin{array}{c}+ \\
p=0.680^{*}\end{array}$ & $\stackrel{+}{+} \underset{p=0.532 * *}{ }$ & $\begin{array}{c}+ \\
p=0.195^{*}\end{array}$ & $\begin{array}{c}- \\
p=0.774 *\end{array}$ \\
\hline Prx6 cytoplasm (strong) & & $\begin{array}{c}- \\
p=0.060 *\end{array}$ & $\stackrel{+}{+}=0.522 * * *$ & 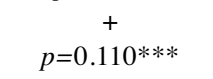 \\
\hline 8-OHdG serum levels $(\mathrm{ng} / \mathrm{ml})$ & & & $p=0.461^{*}$ & $p=0.015^{*}$ \\
\hline 8-OHdG present in cytoplasm & & & & $\begin{array}{c}- \\
p=0.036\end{array} * * *$ \\
\hline
\end{tabular}

*Mann-Whitney $U$-test; **Spearman correlation; ***Pearson Chi-Square test.

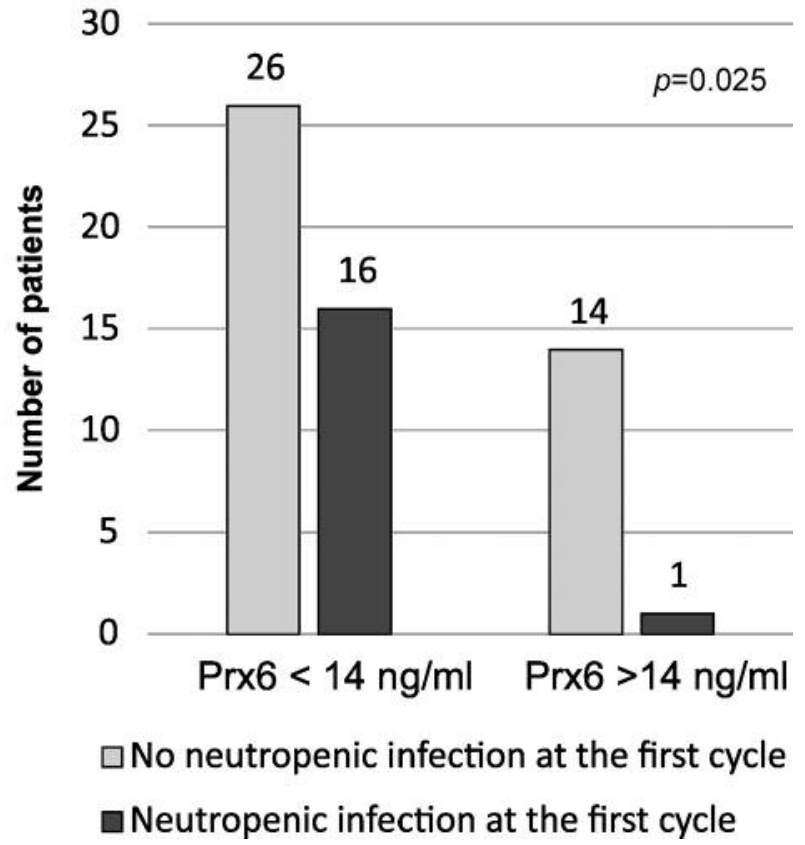

Figure 3. The number of patients with or without first course neutropenic infection according to Prx6 serum levels. p-Value was calculated using Fisher's exact test.

\section{Discussion}

In this study, it is shown for the first time that patients presenting with DLBCL and PCNSL have low levels of circulating immunoreactive Prx6 when compared to healthy controls. Moreover, low serum levels (Prx6 <14 ng/ml) were related to neutropenic infections following the first treatment. Strong cytoplasmic Prx6 expression was also associated with the presence of IPI factors, while in a previous study there was no such association (4).
Prxs are a ubiquitously expressed conserved family of antioxidant peroxidases that also appear to have various other functions $(7,8)$. Prx6 differs from the rest of the Prxgroup by using glutathione as a reducing agent. It also has a phospholipase A2 (PLA2) activity relevant to lung surfactant metabolism (9). Prx6 is overexpressed in many types of neoplasms (10-15) and cancer cells have been shown to benefit separately from peroxidase and phospholipase activities. As cancer cells often suffer from hypoxia and oxidative stress, extensive antioxidant machinery and overexpression of Prx6 can be a feature promoting growth and survival and invasiveness (9).

Prx6 has a major role in phospholipid turnover. It can reduce oxidative insults in phospholipids, thus, restoring the integrity of plasma and organelle membranes and avoiding cell death. It is located in the cytosol, where it readily binds to peroxidised phospholipids, but it also functions in acidic lysosomes where Prx6 can bind and hydrolyse native phospholipids (9). The low levels of serum Prx6 and high tissue levels in our patient cohort could therefore be explained by the high proliferation rate of lymphoma cells that critically need phospholipid turnover (16).

Prx6 seems to be strongly expressed in DLBCL and PCNSL. Strong Prx6 expression in the cytoplasm appears to be related with higher levels of $8-\mathrm{OHdG}$ in the nucleus, which is in agreement with a role in the elimination of reactive oxygen species and prevention of DNA damage. 8-OHdG itself did not correlate with any clinical disease parameters but it has previously been associated with extranodal involvement and high IPI score in DLBCL (2). We have previously shown that Prx6 is associated with worse outcomes in DLBCL (4). We could not demonstrate the prognostic impact of lymphoma cell Prx6 expression, which is probably due to the small sample size analysed in this study. Prx6 expression was, however, associated with adverse clinical features.

Elevated Prx6 serum levels have been reported in patients with breast cancer (17), lung cancer (18) and ovarian 
carcinoma (19). Autoantibodies against Prx6 have been found in patients with lung cancer (18), gastric cancer (20) and oesophageal squamous cell carcinoma (21). In contrast to other types of malignancies, low serum levels of Prx6 in DLBCL and PCNSL patients compared to controls was found. Lower serum levels of Prx6 may reflect different disease biology and redox balance in lymphoma compared to other cancer types. The source of serum Prx6 has not been clearly defined. Expression of Prx6 in various tissues has been shown to rise in marine animal models following bacterial stimuli $(22,23)$. The same effect has been seen in mouse bone marrow-derived macrophages following stimulation with interferon gamma and lipopolysaccharide (24). One study demonstrated translocation of Prx6 to the plasma membrane during neutrophil activation and that this is required for optimal function of nicotinamide adenine dinucleotide phosphate (NADPH) oxidase (25). Other Prxs have also been found in body liquids and shown to modulate inflammation by interacting with toll like receptors and cyclophilin A (7).

Under oxidative stress, Prx6 expression is induced by nuclear factor erythroid 2 related factor 2 (Nrf2) that binds to an antioxidant response element upstream from the PRDX6 gene (9). Nrf2 is known to be one of the principal regulators of the whole antioxidant system and to have antiinflammatory and cytoprotective effects. Recent studies have shown Nrf2 to be an important regulator of innate immunity (26). Therefore, Prx6 may have an immunological function in addition to its other properties.

Several chemotherapeutics cause DNA damage by inducing the production of reactive oxygen species. Together with Prx6's immunological effects, we hypothesized that serum antioxidant capacity might interfere with the host's vulnerability to therapy-related side effects. Because of the retrospective nature of the study, the only side effect that was reliably compiled from hospital records was the incidence of therapy-related infections. In line with this, a strong association between the incidence of neutropenic infections after the first cycle and low serum Prx6 level was found. Currently there are no good biological predictors for infection risk and serum Prx6 shows some potential in lymphoma patients, but this needs to be verified in a prospective clinical setting. This finding also implies that improving hosts' antioxidant capacity might protect the patient from chemotherapy-induced adverse effects. Low albumin levels have been associated with multiple adverse clinical features and it is believed to reflect blood thiol pool and antioxidant capacities (27). In the current study however, albumin was not associated with neutropenic infections and did not correlate with serum levels of Prx6 or $8-\mathrm{OHdG}$. Thus, blood serum albumin and Prx6 appear to have different functions and Prx6 might be more sensitive to predict therapy-related side effects.

Weaknesses of this study include its retrospective nature, the small sample size in all groups and the age disparity between patients and controls. Since there are no Prx6 serum reference values, age seems to be a significant factor affecting serum concentrations, as has previously been seen. This work supports the notion of Prx6 being associated with adverse clinical features in DLBCL and possibly in PCNSL. Interestingly, the pre-treatment serum levels of Prx6 could be potentially used to evaluate the treatment-related risk of neutropenic infection. This finding should be confirmed in a larger prospective study.

\section{Conflicts of Interest}

The Authors state no conflicts of interest regarding this study.

\section{Authors' Contributions}

Kari and Kuusisto designed and wrote the study and analysed data, participated in clinical data and biopsy sample collection. Böhm analysed immunohistochemistry. Haapasaari participated in biopsy sample collection and analysed immunohistochemistry. Teppo assisted with statistical analysis and analysed immunohistochemistry. Karihtala designed the study and assisted with statistical analysis. Hakalahti designed the study. Turpeenniemi-Hujanen analysed data and designed the study. Kuittinen designed and wrote the study and analysed data. All authors reviewed and edited the manuscript.

\section{Acknowledgements}

This study is included in the thesis project of EJM Kari. The Authors thank Anne Bisi, Riitta Vuento and Erja Tomperi for their contribution in clinical laboratory tests.

Funding: This study was conducted as a part of a thesis project with no specific grants. Teppo would like to acknowledge the financial support from the Finnish Medical Foundation, the Finnish medical society Duodecim, the Thelma Mäkikyrö foundation and the Finnish Society for Oncology. Turpeenniemi-Hujanen would like to acknowledge the financial support from the Väisänen Foundation.

\section{References}

1 Martelli M, Ferreri AJM, Agostinelli C, Di Rocco A, Pfreundschuh M and Pileri SA: Diffuse large B-cell lymphoma. Crit Rev Oncol Hematol 87: 146-171, 2013. PMID: 23375551. DOI: $10.1016 /$ j.critrevonc.2012.12.009

2 Peroja P, Pasanen AK, Haapasaari K, Jantunen E, Soini Y, Turpeenniemi-Hujanen T, Bloigu R, Lilja L, Kuittinen $\mathrm{O}$ and Karihtala P: Oxidative stress and redox state-regulating enzymes have prognostic relevance in diffuse large B-cell lymphoma. Exp Hematol Oncol 1: 2, 2012. PMID: 23210982. DOI: 10.1186/ 2162-3619-1-2

3 Pasanen AK, Kuitunen H, Haapasaari K, Karihtala P, Kyllönen $\mathrm{H}$, Soini $\mathrm{Y}$, Turpeenniemi-Hujanen $\mathrm{T}$ and Kuittinen $\mathrm{O}$ : Expression and prognostic evaluation of oxidative stress markers in an immunohistochemical study of B-cell derived lymphomas. Leuk Lymphoma 53: 624-631, 2012. PMID: 21929285. DOI: 10.3109/10428194.2011.624226

4 Kuusisto MEL, Haapasaari K, Turpeenniemi-Hujanen T, Jantunen E, Soini Y, Peroja P, Bloigu R, Karihtala P and Kuittinen O: High intensity of cytoplasmic peroxiredoxin VI expression is associated with adverse outcome in diffuse large B-cell lymphoma 
independently of International Prognostic Index. J Clin Pathol 68: 552-556, 2015. PMID: 25935550. DOI: 10.1136/jclinpath-2014202771

5 Kuitunen H, Tokola S, Siniluoto T, Isokangas M, Sonkajärvi E, Alahuhta S, Turpeenniemi-Hujanen T, Jantunen E, Nousiainen T, Vasala $\mathrm{K}$ and Kuittinen O: Promising treatment results with blood brain barrier disruption (BBBD) based immuno-chemotherapy combined with autologous stem cell transplantation (ASCT) in patients with primary central nervous system lymphoma (PCNSL). J Neurooncol 131: 293-300, 2017. PMID: 27752883. DOI: $10.1007 / \mathrm{s} 11060-016-2293-8$

6 Hans CP, Weisenburger DD, Greiner TC, Gascoyne RD, Delabie J, Ott G, Müller-Hermelink HK, Campo E, Braziel RM, Jaffe ES, Pan Z, Farinha P, Smith LM, Falini B, Banham AH, Rosenwald A, Staudt LM, Connors JM, Armitage JO and Chan WC: Confirmation of the molecular classification of diffuse large B-cell lymphoma by immunohistochemistry using a tissue microarray. Blood 103: 275-282, 2004. PMID: 14504078. DOI: 10.1182/blood-2003-05-1545

7 Ishii T, Warabi E and Yanagawa T: Novel roles of peroxiredoxins in inflammation, cancer and innate immunity. J Clin Biochem Nutr 50: 91-105, 2012. PMID: 22448089. DOI: 10.3164/jcbn.11-109

8 Rhee SG: Overview on Peroxiredoxin. Mol Cells 39: 1-5, 2016. PMID: 26831451. DOI: 10.14348/molcells.2016.2368

9 Fisher AB: Peroxiredoxin 6: a bifunctional enzyme with glutathione peroxidase and phospholipase A2 activities. Antioxid Redox Signal 15: 831-844, 2011. PMID: 20919932. DOI: 10.1089/ars.2010.3412

10 Kinnula VL, Lehtonen S, Sormunen R, Kaarteenaho-Wiik R, Kang SW, Rhee SG and Soini Y: Overexpression of peroxiredoxins I, II, III, V, and VI in malignant mesothelioma. J Pathol 196: 316-323, 2002. PMID: 11857495 . DOI: $10.1002 /$ path.1042

11 Quan C, Cha E, Lee H, Han KH, Lee KM and Kim W: Enhanced expression of peroxiredoxin I and VI correlates with development, recurrence and progression of human bladder cancer. J Urol 175: 1512-1516, 2006. PMID: 16516038. DOI: 10.1016/S0022-5347(05)00659-2

12 Huang C, Sun Z, Zhao Y, Chen X, Jia J and Zhang W: Increased expression of peroxiredoxin 6 and cyclophilin $\mathrm{A}$ in squamous cell carcinoma of the tongue. Oral Dis 17: 328-334, 2011. PMID: 20796224. DOI: 10.1111/j.1601-0825.2010.01730.x

13 Pak JH, Choi WH, Lee HM, Joo WD, Kim JH, Kim YT, Kim YM and Nam JH: Peroxiredoxin 6 overexpression attenuates cisplatin-induced apoptosis in human ovarian cancer cells. Cancer Invest 29: 21-28, 2011. PMID: 21166495 DOI: 10.3109/ 07357907.2010.535056

14 Nicolussi A, D'Inzeo S, Mincione G, Buffone A, Di Marcantonio MC, Cotellese R, Cichella A, Capalbo C, Di Gioia C, Nardi F, Giannini G and Coppa A: PRDX1 and PRDX6 are repressed in papillary thyroid carcinomas via BRAF V600E-dependent and independent mechanisms. Int J Oncol 44: 548-556, 2014. PMID: 24316730. DOI: $10.3892 /$ ijo.2013.2208

15 Yun HM, Park KR, Lee HP, Lee DH, Jo M, Shin DH, Yoon DY, Han SB and Hong JT: PRDX6 promotes lung tumor progression via its GPx and iPLA2 activities. Free Radic Biol Med 69: 367376, 2014. PMID: 24512906. DOI: 10.1016/j.freeradbiomed. 2014.02.001

16 Zhang XH, Zhao C, Seleznev K, Song K, Manfredi JJ and Ma $\mathrm{ZA}$ : Disruption of $\mathrm{G}_{1}$-phase phospholipid turnover by inhibition of $\mathrm{Ca}^{2+}$-independent phospholipase A2 induces a p53-dependent cell-cycle arrest in $\mathrm{G}_{1}$ phase. J Cell Sci 119: 1005-1015, 2006. PMID: 16492706. DOI: 10.1242/jcs.02821

17 Liu F-J, Wang X-B and Cao A-G: Screening and functional analysis of a differential protein profile of human breast cancer. Oncol Lett 7: 1851-1856, 2014. PMID: 24932247. DOI: 10.3892/ol.2014.1978

18 Zhang X, Xiao Z, Li C, Xiao Z, Yang F, Li D, Li M, Li F and Chen $Z$ : Triosephosphate isomerase and peroxiredoxin 6 , two novel serum markers for human lung squamous cell carcinoma. Cancer Sci 100: 2396-2401, 2009. PMID: 19737146. DOI: 10.1111/j.1349-7006.2009.01314.x

19 Tang H-Y, Beer LA, Chang-Wong T, Hammond R, Gimotty P, Coukos G and Speicher DW: A xenograft mouse model coupled with in-depth plasma proteome analysis facilitates identification of novel serum biomarkers for human ovarian cancer. J Proteome Res 11: 678-691, 2012. PMID: 22032327. DOI: 10.1021/pr200603h

20 Hoshino I, Nagata M, Takiguchi N, Nabeya Y, Ikeda A, Yokoi S, Kuwajima A, Tagawa M, Matsushita K, Satoshi Y and Hideaki S: Panel of autoantibodies against multiple tumorassociated antigens for detecting gastric cancer. Cancer Sci 108: 308-315, 2017. PMID: 28064445. DOI: 10.1111/cas.13158

$21 \mathrm{Xu}$ Y-X, Peng Y-H, Chen B, Wu Z-Y, Wu J-Y, Shen J-H, Zheng C-P, Wang S-H, Guo H-P, Li E-M and Xu L-Y: Autoantibodies as potential biomarkers for the early detection of esophageal squamous cell carcinoma. Am J Gastroenterol 109: 36-45, 2014. PMID: 24296751. DOI: 10.1038/ajg.2013.384

22 Godahewa GI, Perera NCN, Elvitigala DAS, Jayasooriya RGPT, Kim G and Lee J: Characterization of a 1-cysteine peroxiredoxin from big-belly seahorse (Hippocampus abdominalis); insights into host antioxidant defense, molecular profiling and its expressional response to septic conditions. Fish Shellfish Immunol 57: 186-197, 2016. PMID: 27542613. DOI: 10.1016/ j.fsi.2016.08.028

23 Priyathilaka TT, Kim Y, Udayantha HMV, Lee S, Herath HMLPB, Lakmal HHC, Elvitigala DAS, Umasuthan N, Godahewa GI, Kang SI, Jeong HB, Kim SK, Kim DJ and Lim BS: Identification and molecular characterization of peroxiredoxin 6 from Japanese eel (Anguilla japonica) revealing its potent antioxidant properties and putative immune relevancy. Fish Shellfish Immunol 51: 291-302, 2016. PMID: 26911410. DOI: 10.1016/j.fsi.2015.12.012

24 Knoops B, Argyropoulou V, Becker S, Ferté L and Kuznetsova O: Multiple roles of peroxiredoxins in inflammation. Mol Cells 39: 6064, 2016. PMID: 26813661. DOI: 10.14348/molcells. 2016.2341

25 Ambruso DR, Ellison MA, Thurman GW and Leto TL: Peroxiredoxin 6 translocates to the plasma membrane during neutrophil activation and is required for optimal NADPH oxidase activity. Biochim Biophys Acta 1823: 306-315, 2012. PMID: 22178385. DOI: 10.1016/j.bbamcr.2011.11.014

26 Battino M, Giampieri F, Pistollato F, Sureda A, de Oliveira MR, Pittalà V, Fallarino F, Nabavi SF, Atanasov AG and Nabavi SM: Nrf2 as regulator of innate immunity: A molecular Swiss army knife! Biotechnol Adv, 2012. PMID: 29277308. DOI: 10.1016/ j.biotechadv.2017.12.012

27 Turell L, Radi R and Alvarez B: The thiol pool in human plasma: The central contribution of albumin to redox processes. Free Radic Biol Med 65: 244-253, 2013. PMID: 23747983. DOI: $10.1016 /$ j.freeradbiomed.2013.05.050

Received July 6, 2019

Revised July 12, 2019

Accepted July 15, 2019 